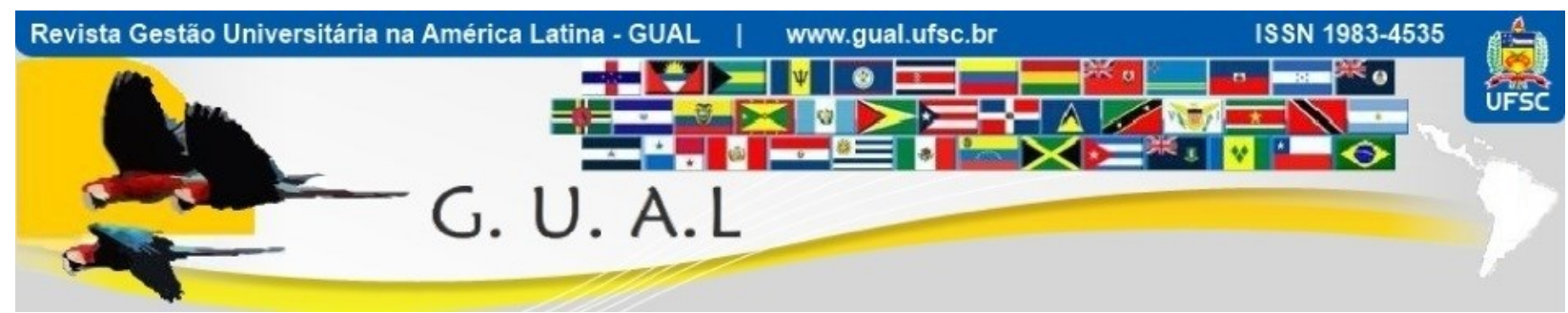

DOI: http://dx.doi.org/10.5007/1983-4535.2017v10n2p71

\title{
EXPECTATIVAS E FRUSTRAÇÕES COM A OFERTA DE CURSOS DE PÓS-GRADUAÇÃO LATO SENSU
}

\section{EXPECTATIONS AND FRUSTRATIONS WITH THE OFFER OF GRADUATE COURSES}

Ricardo Viana Carvalho de Paiva, Doutor Centro Universitário UNA ricardovcp@gmail.com

Danilo de Melo Costa, Doutor Centro Universitário UNA danilo_mcosta@yahoo.com.br

Fábio Roberto Borges, Doutor Universidade Federal de Minas Gerais - UFMG fabiorfborges@gmail.com

Marcus Vinicius de Paula Freitas, Mestrando

Centro Universitário UNA marcus.paulafreitas@gmail.com

Recebido em 16/novembro/2015

Aprovado em 24/janeiro/2017

Sistema de Avaliação: Double Blind Review

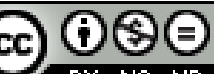

Esta obra está sob uma Licença Creative Commons Atribuição-Uso. 


\title{
RESUMO
}

A educação é um vetor para transformação de realidades na sociedade da informação e, por conta disso, as novas tecnologias vêm trazendo constantes inovações que desafiam modelos tradicionais de ensino. Ao mesmo tempo, a hipercompetitividade mercadológica exige dos profissionais atualização constante e preparação para não somente reagir, mas também transformar a partir de novos cenários. $\mathrm{O}$ artigo apresenta, primeiramente, um benchmarking que explora novas tendências educacionais que estão transformando a maneira como as pessoas aprendem, em exemplos como os Massive Online Courses e Cloud School. Em seguida, o artigo investiga as principais expectativas e frustrações dos profissionais que buscam na oferta de cursos de pós-graduação lato sensu um serviço capaz de atender a essas exigências, a partir do emprego da técnica de sessões generativas, proveniente do design thinking, que se enquadra como uma coleta de dados qualitativa a partir de técnicas projetivas. Os resultados mostram, do ponto de vista mercadológico, um gap significativo entre a entrega do serviço e o serviço esperado em cursos de pós-graduação lato sensu, em aspectos como a frustração com as metodologias adotadas, a deficiente incorporação de tecnologias e o distanciamento entre a prática de mercado e a preparação desempenhada em sala de aula.

Palavras-chave: Pós-Graduação Lato Sensu. Educação. Qualidade em serviços. Novas tecnologias.

\begin{abstract}
Education is a vector for transforming realities into the information society and, because of this, new technologies are bringing constant innovations that challenge traditional educational models. At the same time, market hypercompetitiveness demands of constant professional update and preparation for not only react, but also transform from new scenarios. This paper presents, first, a benchmarking that explores new educational trends that are transforming the way people learn, in examples such as the Massive Online Courses and Cloud School. Then, this paper investigates the main expectations and frustrations of professionals who seek in the offer of postgraduate courses a service able to meet their demands, employing generative sessions, from the design thinking, as a qualitative data collection and projective techniques. The findings shows, from a marketing perspective, a significant gap between the delivery of the service and the service expected in post-graduation courses, in aspects such as frustration with the methodologies adopted, inadequate incorporation of technologies and a distance between the market practice and the preparation performed in the classroom.
\end{abstract}

Keywords: Graduate school. Education. Service quality. New technologies. 


\section{INTRODUÇÃO}

Por detrás do nosso sistema educacional existe um modelo intelectual que é essencialmente uma visão iluminista da inteligência, que compreende a capacidade de realizar certos tipos de raciocínio reducionista e no conhecimento dos clássicos (GABRIEL, 2013). Contudo, os sistemas educativos encontram-se hoje submetidos a novas restrições no que tange a quantidade, diversidade e velocidade de evolução dos saberes (LEVY, 1999). A internet, particularmente trouxe para o campo da educação novas possibilidades de aprendizado com a construção coletiva do saber e democratização do ato de ensinar. Nesse cenário, um modelo tradicional centrado na figura do professor-conteúdo, focado em informação, perde espaço para o papel do professor-interface, focado na mediação e formação (GABRIEL, 2013).

Demo (2013, p.37) chega a colocar que "neste longo percurso através de plataformas digitais que incentivam a autoria aprendemos que a nova geração avança em direção contrária à da escola. Crescendo imersa em nova mídia, não imagina mais como se poderia aprender fora do mundo digital". Essas transformações desencadeiam revoluções em formatos educacionais como, por exemplo, os MOOC (Massive Online Courses), que situados em plataformas digitais, são cursos, na maioria das vezes gratuitos, produzidos por grandes universidades e disponibilizados para milhares de pessoas ao mesmo tempo.

Quando trazemos esta realidade efervescente da educação, com todas as novas possibilidades que se apresentam no mundo contemporâneo, para o cenário da pós-graduação a transformação na oferta dos cursos se torna imperativa. Isso, pois o aluno na pós-graduação está buscando construir o conhecimento que deve impactar diretamente na sua atividade profissional, que, esta sim, já foi totalmente transformada pelas tecnologias da informação. Dessa forma, a expectativa pela educação enquanto serviço cria uma expectativa por parte do estudante que as escolas, em geral, ainda não estão preparadas para entregar e, muitas vezes, sequer entender quais são estas expectativas e as decorrentes frustações. Conforme coloca Demo (2010, p. 118), "as novas tecnologias não parecem ser capazes de inovar as "tecnologias do espírito" - estas continuam vetustas". Assim, a compreensão da nova realidade deve preceder quaisquer mudanças no uso, inserção e adaptação de novas tecnologias e adequações a novas realidades.

Neste contexto, este artigo busca apresentar um quadro acerca das expectativas e frustrações com a qualidade dos serviços oferecidos em ofertas de cursos de pós-graduação 
lato sensu. Para capturar as sensações e sentimentos relacionados utilizou-se uma metodologia baseada em técnicas contemporâneas inspiradas no design thinking, que emergiram a partir do crescente uso de técnicas projetivas, realizando sessões generativas com grupos de alunos e prospects de IES. Antes da apresentação dos resultados da pesquisa, o artigo apresenta um quadro geral da pós-graduação lato sensu no Brasil e possibilidade de enxergar a educação como serviço pela ótica do marketing, sem que isso seja um restritor do seu papel de formação, mas como uma entrega que precisa adequar-se às expectativas daqueles que a consomem. Além disso, um benchmarking contribui para situar macrotendências relacionadas a educação que perpassam o cenário atual do sistema de ensino.

\section{PÓS-GRADUAÇÃO LATO SENSU}

A educação exerce grande influência na mobilidade social, em especial a educação superior, possibilitando que por meio da mesma os indivíduos de classes com menor poder aquisitivo tenham oportunidades de crescimento profissional e de renda, conforme observa Canuto (1987). Atenta a essa demanda, a iniciativa privada cresceu rapidamente, com números mais expressivos que o setor público, ainda que muitas vezes a qualidade do seu serviço tenha sido comprometida (SAMPAIO, 2011).

Silva Jr. e Sguissardi (2001) analisaram na ocasião a existência de certa crise relacionada ao sistema federal de ensino superior, pois o mesmo não acompanha a crescente demanda da população e não se atualiza o suficiente para preparar adequadamente os universitários para o mercado de trabalho. A pós-graduação, neste sentido, traz um novo campo de possibilidades de preparação dos alunos para o mercado de trabalho.

Os cursos de pós-graduação lato sensu compreendem os programas de especialização e também incluem os cursos nomeados como Master in Business Administration (MBA), segundo o Ministério da Educação (2014). Já os cursos de pós-graduação scricto sensu compreendem os programas de mestrado e doutorado, orientados para a formação acadêmica, também de acordo com o Ministério da Educação (2014).

As organizações empregadoras e os trabalhadores enxergam na pós-graduação lato sensu uma alternativa viável para se obter o domínio de determinada especialidade ou de atualização profissional, nas mais diversas áreas, como uma resposta às exigências do mercado de trabalho. O caráter temporário, a versatilidade, o dinamismo e a agilidade nas respostas a necessidades específicas, permitem com que tais cursos sejam vistos como 
instrumentos de disseminação do conhecimento por organizações, estudiosos e profissionais (PILATI, 2006).

A expansão do número de cursos de pós-graduação lato sensu é constante, pelo menos na última década, embora seja difícil encontrar levantamentos confiáveis acerca deste crescimento. Pilati (2006) afirma que, no período de 2001 a 2003, houve um crescimento de 47\% no número de instituições que oferecem cursos de especialização em nível de pósgraduação. Conforme menciona Fonseca (2004), o crescimento desse nível de ensino é resultado de alguns fatores, como: a expansão do setor privado; a ampliação do mercado de trabalho que demanda novas formas e modalidades de cursos e níveis de ensino; e, por ser uma modalidade de ensino auxiliada por políticas e legislações mais flexíveis o que gerou, particularmente na área privada, a oferta de cursos desvinculados dos critérios acadêmicos mínimos de qualidade.

Pela razão de serem abertos, amplos e terem políticas e legislações mais flexíveis, os cursos de pós-graduação lato sensu enfrentam uma série de dificuldades conceituais, legais e de dados estatísticos (COSTA, 2007). De acordo com o autor, em relação à dimensão conceitual, existem algumas dificuldades de especificação, já que a lei brasileira informa que a pós-graduação latu senso envolve cursos de aperfeiçoamento, mas não faz nenhuma distinção em relação à especialização e os pré-requisitos de oferta. Sobre a dimensão do marco legal da pós-graduação, permanecem pontos ambíguos e sem um suporte legal que estabeleça condições adequadas para o desenvolvimento e consolidação destes cursos. Ainda de acordo com Costa (2007), pouco trabalho foi realizado com o objetivo de estabelecer um panorama da pós-graduação lato sensu no Brasil, inclusive no senso de educação superior realizado pelo Ministério da Educação (MEC) e nas informações da Coordenação de Aperfeiçoamento de Pessoal de Nível Superior (CAPES).

Sendo assim, segundo Fonseca (2004), se faz necessário um debate mais aprofundado para repensar-se a política da pós-graduação, o seu caráter conceitual, formativo e regulador, apontando, dentre outros, como importantes questões para a sua reestruturação: uma política de pós-graduação articulada, nos níveis de mestrado profissional, mestrado acadêmico e especialização; o papel regulador do MEC/CNE-CES/Capes; e a aprovação pelos conselhos superiores da instituição do projeto pedagógico do curso. De acordo com Pilati (2006), o aperfeiçoamento da regulação desse nível de ensino, deve estar alinhado com o objetivo de 
definir a especificidade e a identidade da especialização, assim como de preservar a qualidade que é esperada dos cursos de pós-graduação lato sensu.

\section{A OFERTA DE PÓS-GRADUAÇÃO LATO SENSU SOB A ÓTICA DO MARKETING}

Para Silva Jr. e Sguissardi (2001) a mercantilização da educação superior se torna responsável por uma acirrada disputa institucional, fazendo com que os gestores destas instituições flexibilizem ao máximo suas ações administrativas com o objetivo de sobreviver às duras disputas do mercado. Dessa forma, constata-se o crescimento de cursos baratos e de guerra de preços, o que, diante da baixa relação ingressante/vaga, contribuem para a queda das mensalidades e o aumento da competição no setor. Outro fenômeno decorrente do aumento da competição no setor é o de concentração. Em 2009, 5\% das instituições privadas de ensino superior concentraram 54,6\% do faturamento total do setor (HOPER, 2009). A resposta para manutenção da qualidade e correto ajuste entre expectativas dos alunos e do mercado em relação às ofertas, passa pela compreensão das expectativas e desejos do consumidor, adotando estratégias de marketing.

Os cursos de pós-graduação podem ser entendidos a partir da perspectiva mercadológica como serviços, devido às suas características, conforme classificação de Lovelock e Gummeson (2004): Intangibilidade, pois os cursos não podem ser apalpados ou experimentados anteriormente ao seu início ou sua aquisição; Perecibilidade, ao passo que não podem ser estocados; Variabilidade, à medida que variam de acordo com a instituição prestadora do serviço, dos coordenadores, professores, etc.; e, Inseparabilidade, de forma que os cursos são produzidos e consumidos ao mesmo tempo.

Conforme o número de instituições de ensino privado com ofertas de cursos de pósgraduação aumenta, torna-se mais importante para estas organizações do setor de serviços diferenciarem seus produtos de maneira significativa aos consumidores. Para isso, segundo Lovelock, Wirtz e Hemzo (2011), a estratégia de posicionamento deve preocupar-se em criar, comunicar e manter diferenciais que serão notados e valorizados pelos consumidores com que a empresa gostaria de manter um relacionamento de longo prazo e que foram selecionados como público-alvo.

Trazendo a abordagem mnemônica, popularizada no marketing com os 4Ps, Ivy (2008) aponta quais seriam os 7Ps do marketing para oferta de MBAs, conforme mostra a Fig. 1. 


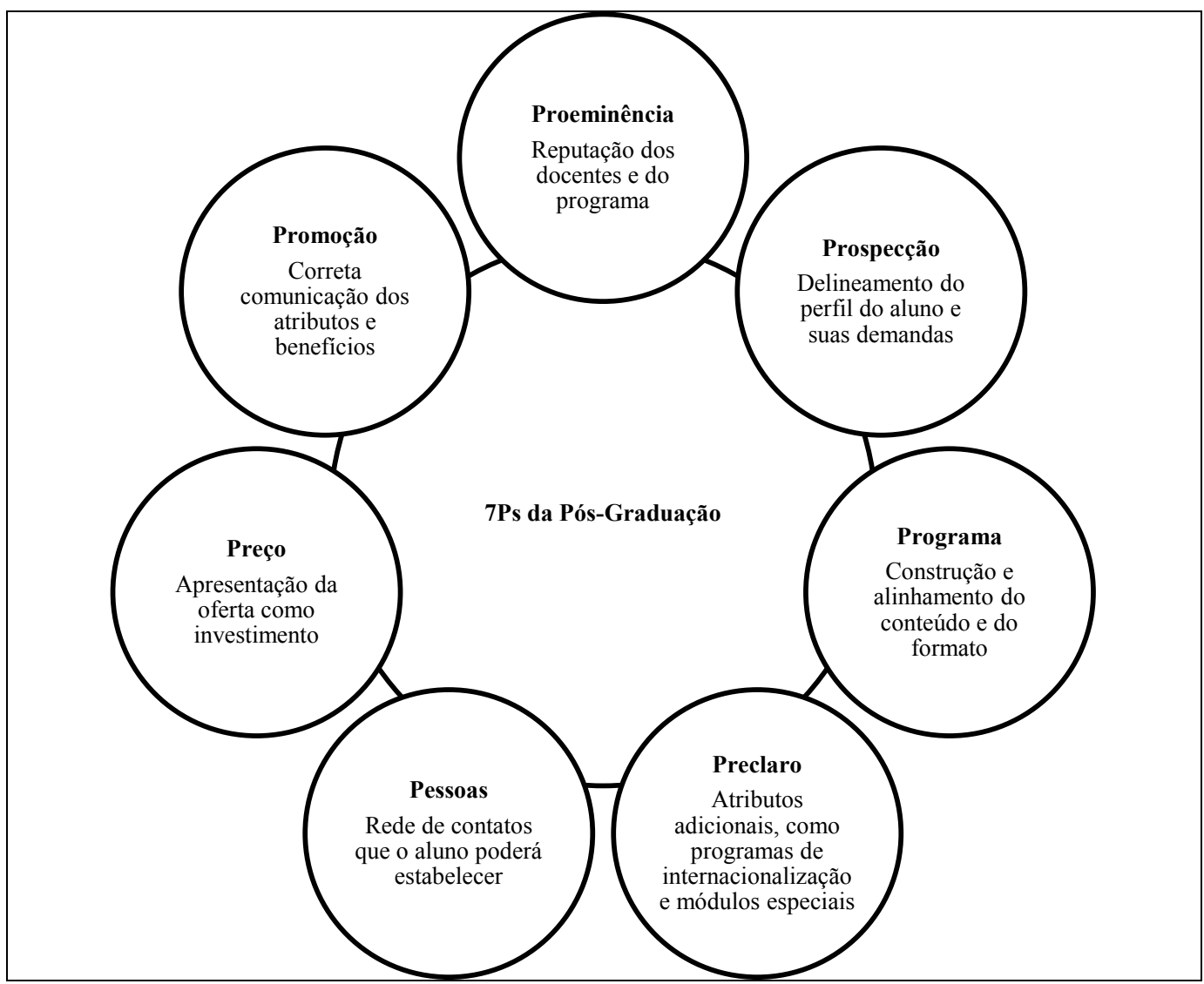

Figura 1 7Ps da Pós-Graduação.

Fonte: Adaptado e traduzido de Ivy (2008).

Conforme mostra a Fig. 1, existem diversos elementos a serem orquestrados para a oferta de cursos de pós-graduação, que vão desde os aspectos básicos do marketing como preço e promoção, até especificidades como adequação do programa a realidade do mercado e reputação do corpo docente. Prêmio

Nos dias de hoje a necessidade de ser inovador e crescer através da inovação é um imperativo para as estratégias de líderes empresariais de todo o mundo. Durante o processo de inovação, conforme colocam Bitner e Brown (2008), há evidências consideráveis de que as empresas, que incorporam os pontos de vista dos clientes em seus processos de desenvolvimento de produtos são mais bem-sucedidas. Assim, para os autores, um resultado importante da inovação com foco no cliente é a melhoria da qualidade de vida dos cidadãos do mundo. Se a pesquisa de inovação do serviço é realizada a partir do ponto de vista do cliente e aplicada em algumas das suas necessidades críticas, por exemplo, saúde e educação, então este resultado otimista parece bastante provável. Assim, conforme alertam Bitner e Brown (2008), além da educação da força de trabalho futura, existe uma enorme necessidade 
de pesquisa básica e aplicada que aborde a inovação de serviços e questões de economia de serviços globais.

O framework apresentado na Fig. 2 mostra a relação entre a expectativa em relação ao serviço e sua percepção por parte do consumidor, formada pelo serviço de fato oferecido pela empresa.

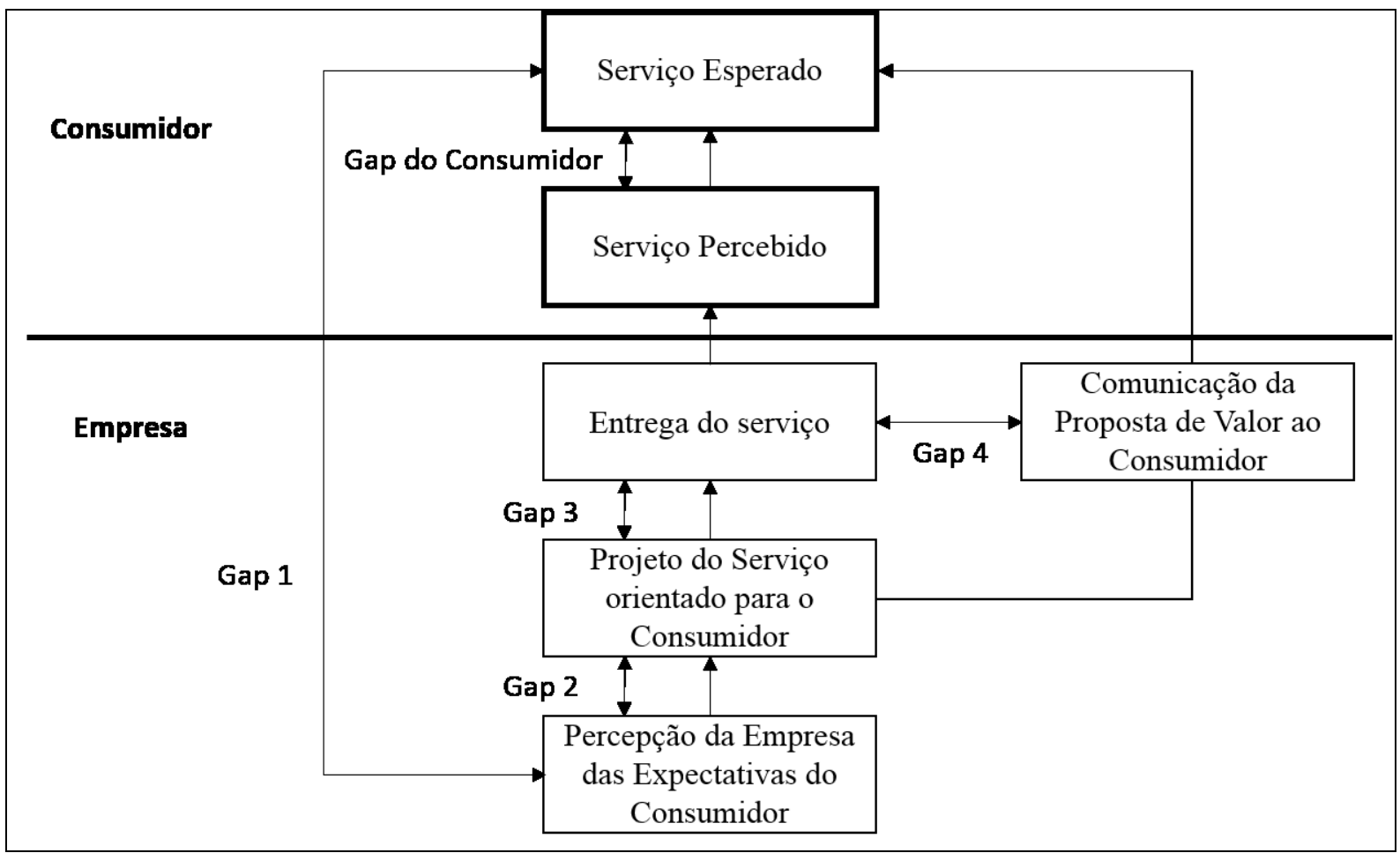

Figura 2 Framework dos Gaps na Entrega de Serviços.

Fonte: traduzido de Zeithaml et al (2006, p. 35).

Conforme mostra a Fig. 2, o Gap 1 está relacionado à não compreensão por parte da organização daquilo que deseja o consumidor, o Gap 2 advém da incapacidade da organização em transformar sua oferta para algo mais próximo do que entende ser a expectativa do cliente, a partir dos recursos que possui, o Gap 3 é a dificuldade em operacionalizar da maneira adequada o serviço conforme foi programado, e, o Gap 4 está relacionado ao fato de não cumprir as promessas feitas em sua comunicação aos consumidores. Todos esses gaps influem de forma mais ou menos abrangente no principal gap que pode ocorrer, que é a diferença entre a expectativa do serviço por parte do cliente e sua percepção do mesmo. Quanto maior for a distância negativa entre a percepção e a expectativa do serviço, mais insatisfeito estará o cliente com a entrega. Por isso, esse artigo traz um benchmarking sobre práticas e tendências contemporâneas de ensino em geral (Cap. 4), e também mostra quais são 
as expectativas em relação a esse serviço que demandam os jovens e o mercado de trabalho atualmente a partir da metodologia de pesquisa empregada (Cap. 5 e 6).

\section{NOVAS PERSPECTIVAS PARA O ENSINO}

Com o objetivo de traçar um panorama mais claro da educação, foi feito um benchmarking da educação com as tendências do setor educacional e quais as empresas que já fazem uso de tais inovações. De acordo com Camp (1989) benchmarking pode ser definido como o processo de pesquisa à procura de novas ideias, métodos, práticas, processos com o objetivo de adotar as práticas ou adaptar os bons aspectos e implementá-las para se tornar o melhor.

Uma grande tendência do setor educacional é a evolução do ensino a distância, a medida que atualmente os cursos online crescem exponencialmente em quantidade e evoluem bastante em qualidade. Em geral, o curso online tem várias vantagens, das quais pode se destacar: flexibilidade de local e horário; economia de tempo e dinheiro; uniformização e rápida atualização; maior controle da instituição e do próprio aluno sobre o seu aprendizado; e, o fato de que cada um pode estudar no seu próprio ritmo. De acordo com Lévy (1999), os especialistas nesse campo reconhecem que a distinção entre ensino presencial e ensino a distância, será cada vez menos pertinente, já que o uso das redes de telecomunicações e dos suportes multimídias interativos vem sendo progressivamente integrado às formas mais clássicas de ensino.

A grande evolução do EAD nos últimos anos deve-se ao surgimento do Massive Open Online Course (MOOC), serviço hospedado em uma plataforma online que oferece cursos virtuais gratuitos, muitas vezes produzidos por grandes universidades do mundo, como Harvard e MIT. Um exemplo do sucesso desta modalidade é o Cousera, portal de educação com sede no Vale do Silício, fundado por professores da Universidade de Stanford, que oferece 331 cursos gratuitos de 62 grandes universidades dos Estados Unidos, vários países da Europa, Austrália, China, Japão e México (COURSERA, 2014).

Outra tendência é o Cloud School, ou "escola na nuvem", que é o impacto da revolução online na cultura, no comportamento e em todas as fases do processo de aprendizagem do estudante e de ensino do professor. O ensino híbrido, os jogos, as plataformas adaptativas e a sala de aula invertida auxiliam professores e alunos no processo de aprendizagem conectando-os dentro e fora da sala de aula. Um exemplo de ensino hibrido 
é o trabalho realizado pela iSchool, criada em 2007 para repensar a educação e adequá-la à nova realidade (ISCHOLL, 2014). Os professores decidem quando as aulas serão off-line ou online. E quando os alunos estão trabalhando sozinhos, um software centraliza e registra as atividades, permitindo que os professores saibam o que cada aluno fez. A educação baseada em jogos pode ser exemplificada pelo Institute of Play de Nova York, onde os estudantes aprendem de forma inovadora e interativa através de jogos e desafios (INSTITUTE OF PLAY, 2014).

$\mathrm{Na}$ economia do conhecimento, símbolos de status vão competir cada vez mais com novas habilidades. Diante disso, a Perestroika, fundada em 2007 em Porto Alegre, começou como uma escola de criação publicitária, e hoje é uma escola de atividades criativas que tem cursos desde gastronomia ao design (BOURROUL, 2014). Ao passo que o Brasil tem um cenário promissor que o coloca em um papel de destaque na criação de novos negócios, é cada vez maior o número de cursos de empreendedorismo e maior o incentivo das iniciativas públicas e privadas pela inovação e o surgimento de novas startups.

De acordo com pesquisa realizada pela Endeavor (2012), organização de apoio ao empreendedorismo, seis em cada dez jovens brasileiros querem abrir um negócio, sendo essa uma das maiores taxas do mundo. Nesse sentido, pode-se citar a Team Academy, que é uma faculdade de pós-graduação da Finlândia onde os alunos aprendem a serem inovadores na prática, tendo um auxílio de coaching no desenvolvimento dos projetos (TEAM ACADEMY, 2014).

Nos dias atuais as instituições educacionais não têm outra opção a não ser adotar a transparência, pois a audiência está cada vez mais atenta e pode ver, escutar e discutir sobre todas as escolas, professores e serviços educacionais. Nos Estados Unidos a CourseRank é uma plataforma que oferece aos estudantes, de forma anônima, a avaliação dos cursos, agendas semanais e anuais, e grau dos planejadores. Os usuários podem pesquisar cursos por classificação, departamento, palavras-chave e compromisso de tempo necessário. As faculdades também podem usá-lo como uma ferramenta de feedback das classes. A maioria das universidades americanas possui sua própria versão personalizada do site.

\section{METODOLOGIA}

Segundo Malhotra (2001), a pesquisa qualitativa pode ser definida como uma técnica de pesquisa não-estruturada, exploratória, baseada em pequenas amostras, que proporciona 
insights e compreensão do contexto do problema. O presente artigo pode ser classificado como exploratório, uma vez que buscou investigar fatores não estruturados formalmente em processos, ideias e dados e proporcionar melhor visão e compreensão da natureza do problema, com caráter de descoberta (GONÇALVES; MEIRELLES, 2004; VERGARA, 2005).

O artigo apresenta os resultados da aplicação de técnicas de pesquisa projetivas, que, de acordo com o Ibope (2014), têm por objetivo facilitar o pensamento e ativar o emocional dos participantes. A técnica projetiva não se preocupa tanto com a linguagem racional, pois incentiva o imaginário das pessoas e a expressão da opinião e da percepção além do verbal, tendo como métodos mais tradicionais a colagem e a personificação (IBOPE, 2014).

De acordo com Vieira e Tíbola (2005), a utilidade das técnicas projetivas é evidenciada quando:

1. A informação que é desejada não pode ser alcançada através de métodos diretos;

2. A pesquisa é exploratória com o objetivo de proporcionar entendimento e compreensão; e,

3. Por serem complexas, as informações não devem ser coletadas e compreendidas de maneira ingênua.

Segundo Marchetti (1995) apud Vieira e Tibola (2005), mesmo aparentando simplicidade, a utilização das técnicas projetivas em marketing deve ser feita com bastante cuidado, pois as dificuldades de se avaliar a validade e a confiabilidade dos testes projetivos podem conduzir a resultados alterados.

Dentre as técnicas projetivas possíveis este estudo utilizou a abordagem das sessões colaborativas, uma técnica muito utilizada em salas de aula e em ambientes de e-learning. As sessões colaborativas são reuniões de grupo para projeção de cenários e possibilidades a partir da colocação de problemas complexos para debate. A construção coletiva das respostas para as questões colocadas enriquece as proposições formuladas com pontos de vista e opiniões divergentes (ISOTANI; MIZOGUCHI, 2006).

Para que o trabalho alcançasse seus objetivos um total de 24 pessoas participaram deste estudo, sendo 8 alunos de pós-graduação da Instituição de Ensino Superior de Belo Horizonte $\mathrm{ABC}, 8$ alunos de pós-graduação da Instituição de Ensino Superior de Belo Horizonte DEF e 8 sujeitos que desejam cursar um curso de pós-graduação dentro de alguns meses, como mostra a Tabela 1. 
Tabela 1 Participantes das Sessões Colaborativas.

\begin{tabular}{c|c|c}
\hline Alunos de Pós e Egressos - IES ABC & Alunos de Pós e Egressos - IES DEF & Futuros alunos \\
\hline $\begin{array}{c}\text { Pessoas que já viveram ou estão vivendo a } \\
\text { experiência de uma pós-graduação na } \\
\text { Instituição de Ensino Superior 1 }\end{array}$ & $\begin{array}{c}\text { Pessoas que já viveram ou estão vivendo a } \\
\text { experiência de uma pós-graduação na } \\
\text { Instituição de Ensino Superior 2 }\end{array}$ & $\begin{array}{c}\text { Pessoas que } \\
\text { pretendem cursar } \\
\text { uma pós-graduação } \\
\text { nos próximos } \\
\text { meses }\end{array}$ \\
\hline
\end{tabular}

Fonte: dados da pesquisa.

\section{ANÁLISE DOS DADOS}

Nesta seção serão apresentadas as análises dos dados coletados através de técnicas projetivas e sessões colaborativas, através da divisão por categorias de análise, de acordo com as perguntas realizadas em temas afins. $\mathrm{Na}$ etapa de análise dos dados utilizaram-se as técnicas de análise de conteúdo e análise temática. As categorias de análise encontradas, a partir das construções coletivas produzidas nas seções colaborativas foram: Modelo Multiplataforma; Experiências Práticas; Interação entre Alunos; Uma Nova Sala de Aula; Discurso de Valorização; Grade Curricular mais Flexível e Personalizada.

\subsection{MODELO MULTIPLATAFORMA}

Em um primeiro momento os participantes foram estimulados a pensar sobre como seria um novo modelo de educação continuada. Foi possível categorizar uma gama de respostas apontando para a urgência de ofertas de pós-graduação que apresentassem um modelo multiplataforma. Foi mencionada pelos participantes a utilização de sistemas de aulas em videoconferência com os professores e também vídeo-aula, onde os professores gravam as aulas e disponibilizam em plataformas digitais.

A frase a seguir representa o que os participantes propuseram a esse respeito: "Eu acho muito interessante e, além disso, você estuda de maneira didática. É cansativo você chegar numa aula hoje, o professor ficar duas horas falando na sua cabeça, jogando matéria, às vezes lendo um código. É impressionante, você não aprende nada". A Fig. 3 mostra um quadro gerado por um dos grupos acerca da urgência desse novo modelo multiplataforma. 


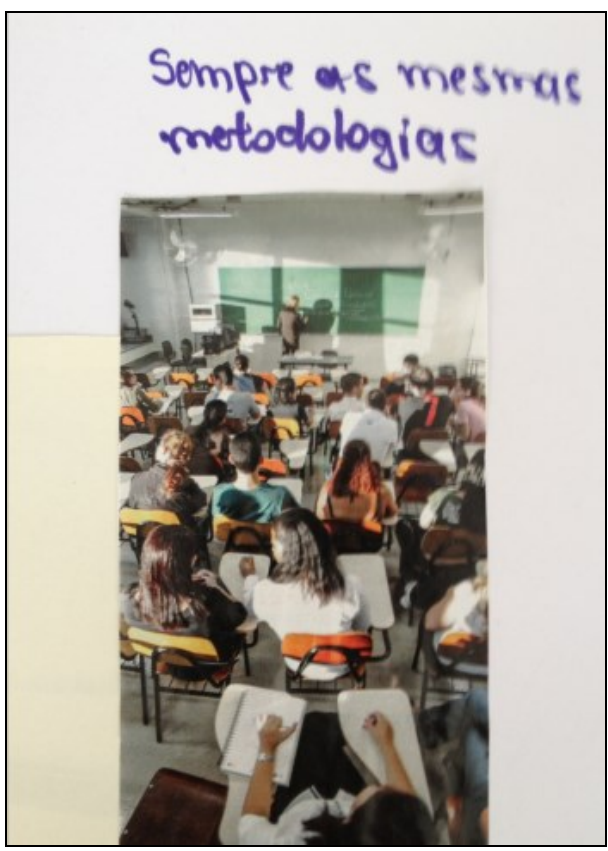

Figura 3 Metodologia de Ensino e Estrutura. Fonte: dados da pesquisa.

A Fig. 3 evidencia a frustração dos estudantes em encontrarem na pós-graduação a metodologia de ensino e a estrutura tradicional com os quais estão acostumados na graduação ou no ensino básico. A expectativa dos participantes é de que a pós-graduação possa apresentar uma metodologia mais dinâmica, não centrada somente na apresentação de conteúdo no formato de sala de aula tradicional, mas que aproveite novas possibilidades trazidas por meio digitais.

Vale ressaltar, conforme colocou Lévy (1999), que fazer uso de todas as novas tecnologias na educação e na formação sem alterar os formatos de validação das aprendizagens, seria o mesmo que inchar os músculos da instituição escolar, bloqueando o desenvolvimento de seus sentidos e seu cérebro.

\subsection{EXPERIÊNCIAS PRÁTICAS}

Para os participantes o novo modelo de educação continuada deve proporcionar experiências práticas. Os laboratórios foram mencionados como demandas para todas as áreas da educação, pois a vivência de um laboratório é considerada uma grande forma de aprendizagem. A pesquisa de campo também foi citada como alternativa, porém seu formato deve ser inovador para a geração de interesse e motivação das pessoas. A frase de um dos participantes da pesquisa ressalta este ponto: "Por que não ter expedições criativas, viagens 
pra ver outras soluções, outras pessoas, porque precisa ser necessariamente dentro da sala de aula?".

De acordo com os participantes, as instituições de ensino devem se aproximar mais do mercado, estarem mais conectadas com as ofertas de emprego, estágios e outras oportunidades, até mesmo um Programa de Trainee Acadêmico. Conforme mencionado por um dos participantes: "Poderia ter uma forma de intercâmbio, ou até um estágio também. Eu acho que assim não tem, eu nunca vi uma pós que tenha estágio. Mas para acontecer isso tem que ter uma parceria concreta."

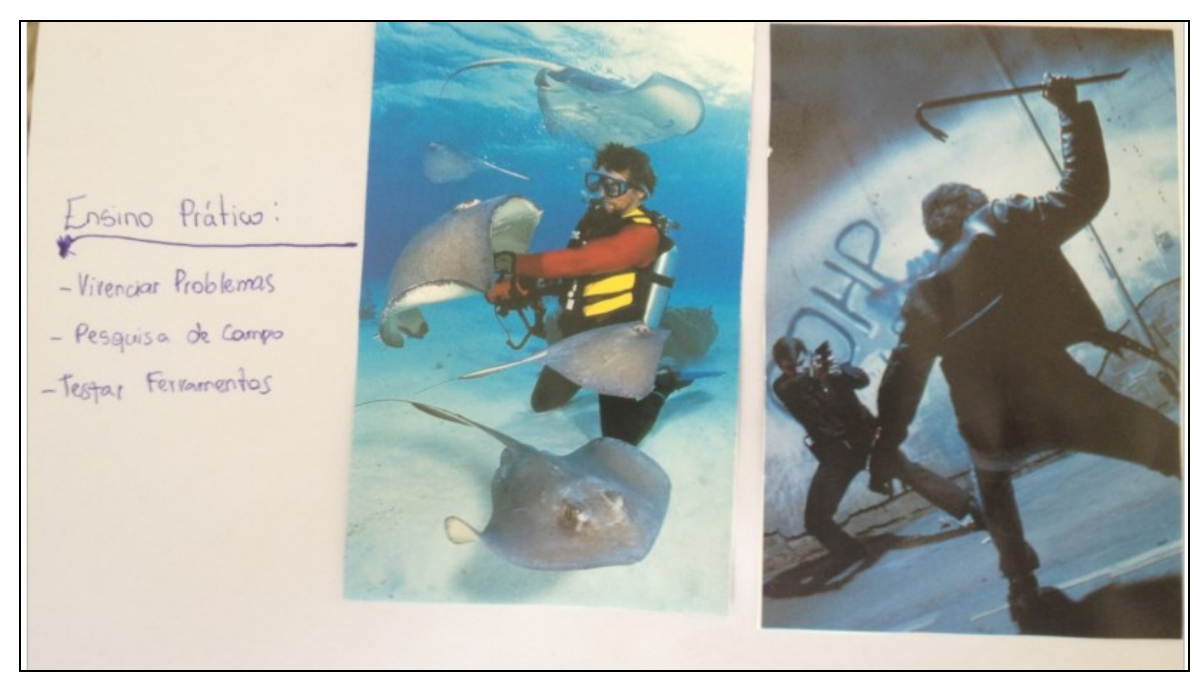

Figura 4 Vivência e Ensino.

Fonte: dados da pesquisa.

A Fig. 4 evidencia a percepção dos estudantes de que a pós-graduação deve ser um lugar seguro para aprender a lidar com problemas práticas, sendo o professor o guia nesse processo de aprendizado e os outros estudantes como pares que compartilham sua vivência práticas.

Nesse processo, o professor torna-se um animador da inteligência coletiva dos grupos, segundo Levy (1999). Ainda de acordo com o autor, sua atividade será centrada no acompanhamento e na gestão das aprendizagens: o estímulo à troca dos saberes, a mediação relacional e simbólica, a pilotagem personalizada dos percursos de aprendizagem, entre outros. 


\subsection{INTERAÇÃO ENTRE ALUNOS}

Outro ponto mencionado pelos participantes do presente estudo foi à interação, pois o processo para a busca da educação contínua deve seguir os princípios de colaboração e possibilidades de comunicação efetivas. Na educação continuada à interação e integração entre a turma é necessária e importante para o desenvolvimento de conhecimento e experiência. Segundo os participantes, a própria instituição deveria se dedicar a criar ferramentas que proporcionem maior integração da turma. Como exemplo foi mencionado grupos de discussão online com a possibilidade de continuar a discussão fora da sala de aula, com mediação do professor ou não.

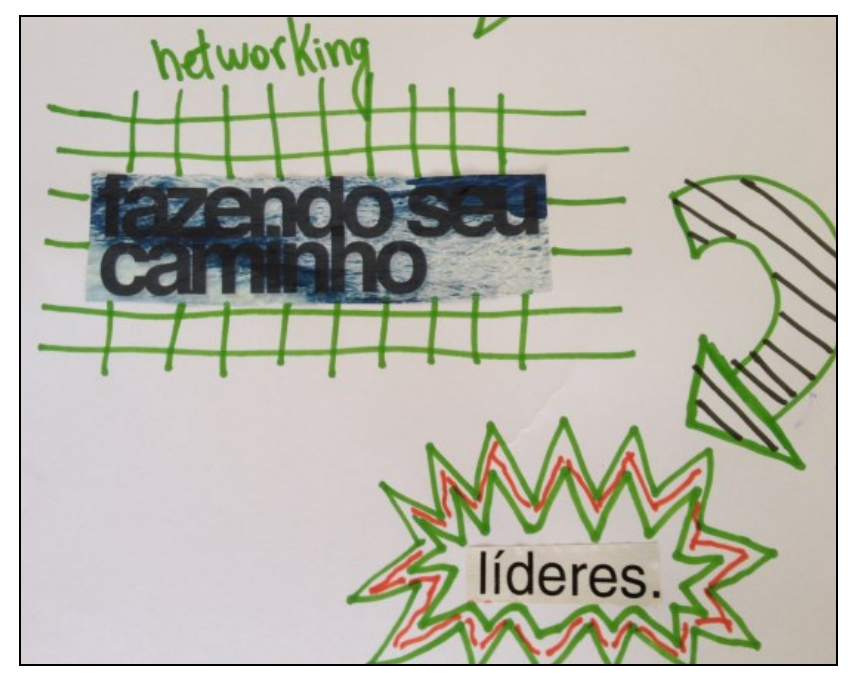

Figura 5 Interação entre alunos.

Fonte: dados da pesquisa.

A Fig. 5 ratifica a necessidade dos alunos de serem mais integrados compartilhando conhecimentos e também a construção de networking. Um papel importante da pós-graduação para os alunos é a troca de experiências e contatos profissionais. Assim, o caminho mais promissor para o ensino, segundo Levy (1999), que traduz a perspectiva da inteligência coletiva no domínio educativo, é a aprendizagem cooperativa, onde professores e estudantes partilham os recursos materiais e informacionais de que dispõem.

\subsection{UMA NOVA SALA DE AULA}

Os participantes levantaram alguns problemas da sala de aula atual, onde os termos e expressões mais utilizadas foram: chata; entediante; burocrática; estática; dificulta a organização dos trabalhos de grupos; pouco tecnológica; recursos multimídia ruins; e, 
projeções de baixa qualidade. Nas empresas em que trabalham ou já visitaram os participantes da pesquisa relataram já terem vivenciado ambientes diferenciados e sentem que eles fazem a diferença na convivência profissional. Para os participantes, a infra-estrutura para uma instituição que ofereça educação continuada deve seguir a mesma evolução das novas tecnologias e utilizá-las dentro das salas de aula, para promover maior interação entre alunos e professores.

\subsection{DISCURSO DE VALORIZAÇÃO}

De acordo com os participantes, o mercado profissional exige uma postura de alerta permanente, com práticas de educação continuada. A educação continuada deve proporcionar novas e contínuas maneiras de se obter o conhecimento. As ofertas de educação continuada devem assegurar que os seus alunos consigam abrir seus horizontes e se inserir no mercado de trabalho com maior facilidade, segundo os participantes. Uma frase que exemplifica a discussão em torno desse tema é: "Se é para ter um modelo, ele precisa facilitar o nosso campo de visão profissional, sempre nos aperfeiçoando de acordo com o mercado, abrindo as portas com oportunidades cada vez melhores".

\subsection{GRADE CURRICULAR MAIS FLEXÍVEL E PERSONALIZADA}

Os participantes mencionaram a importância da carga horária customizada de acordo com a demanda dos alunos, proporcionando maior possibilidade de aprofundamento, neste novo modelo de educação. A frase a seguir de um dos participantes do estudo demonstra essa preocupação: “O modelo de carga horária está muito banal. A instituição teria que oferecer uma maior disposição para aprofundar um determinado tema que eu possa estar interessado. Eu acho a questão de você entrar na faculdade, ou na pós-graduação, deveria ser mais bem planejado, junto com a própria faculdade".

Esta tendência de personalização é uma realidade nos negócios, sendo que a customização em massa é uma das grandes revoluções na forma de atender às demandas do consumidor. A perspectiva de o aluno encontrar um curso que não tenha tal personalização confronta diretamente com suas expectativas provenientes de outros produtos e serviços que consume. Assim, a demanda de informação não apenas conhece um enorme crescimento quantitativo, ela sofre também uma profunda mutação qualitativa no sentido de uma necessidade crescente de diversificação e de personalização (LÉVY, 1999). Por isso, tal 
demanda de flexibilização e customização emerge como expectativa na oferta de cursos de pós-graduação lato sensu.

\section{CONSIDERAÇÕES FINAIS}

Sob o aspecto mercadológico é pouco comum que exista uma discrepância tão grande entre as expectativas em relação à um serviço e o formato em que o mesmo é geralmente entregue, quando existem recursos disponíveis a um custo razoável para a alteração no padrão da oferta. Contudo, a educação pensada como um serviço sofre com dificuldades de atualização devido a tradições de ensino que precisam ser consideradas juntamente com o pensamento de mercado (GABRIEL, 2013). Dessa forma, a questão parece ser:

Como manter as práticas pedagógicas atualizadas com esses novos processos de transação de conhecimento? Não se trata aqui de usar as tecnologias a qualquer custo, mas sim de acompanhar consciente e deliberadamente uma mudança de civilização que questiona profundamente as formas institucionais, as mentalidades e a cultura dos sistemas educacionais tradicionais e, sobretudo os papéis de professor e de aluno (LEVY, 1999, p. 172).

Os dados da pesquisa apontam para uma grande expectativa dos alunos pela apresentação de situações práticas em sala de aula. Mas é preciso refletir sobre qual prática desejam os alunos? A prática por si só não traz nenhum ganho sensível para a formação. A simples apresentação de uma prática de trabalho em sala de aula pode ser traduzida como verdade pelos alunos. Por isso, é preciso ensinar o aluno a refletir sobre a prática, criar novas práticas, transgredir ditas regras de ação e propor mudanças. Então, a que se pontuar que, embora o aluno tenha a expectativa de vivenciar a prática em sala de aula, o professor deve ser um condutor para que ele tenha ferramentas e capacidade criativa para engendrar as próprias maneiras de lidar com as diferentes situações que se apresentarão em seu cotidiano.

As expectativas dos alunos, dessa forma, dão subsídio para compreender qual tipo de oferta de pós-graduação os mesmos desejam, para a partir desse ponto serem construídos cursos que entreguem o valor esperado. Contudo, é papel do corpo docente interpretar essas expectativas e traduzir esses elementos em cursos que estejam mais afinados com as demandas que emergem do campo do mercado. A partir de então, os alunos, antes de qualquer disciplina, devem compreender qual é o caminho, o programa, o percurso que contribuirá para que ele tenha os insumos necessários e a estrutura de pensamento organizada para alcançar os resultados que espera em seu campo de atuação. Essa perspectiva, contudo, não deve servir como desculpa para uma simples repetição na pós-graduação de práticas de ensino de outros 
níveis educacionais. A pós-graduação apresenta uma demanda que difere qualitativamente em termos atributos e benefícios esperados e para isso há também que exercitar a capacidade de pensar abordagens e práticas de ensino que se adaptem às expectativas apresentadas nesse artigo.

Conforme colocou Levy (1999), a demanda de formação não apenas conhece um enorme crescimento quantitativo, ela sofre também uma profunda mutação qualitativa no sentido de uma necessidade crescente de diversificação e personalização. Assim, os indivíduos irão tolerar "cada vez menos seguir cursos uniformes e rígidos que não correspondem a suas necessidades reais e à especificidade de seu trajeto de vida" (LEVY, 1999, p. 169). Neste contexto, a criatividade e o pensamento crítico são habilidades essenciais, não apenas para jovens e estudantes, mas principalmente para professores e educadores. Pois, "o desapego aos modelos tradicionais e ao status quo, [...] a iniciativa e a colaboração são características que levarão o professor 1.0 para o patamar 2.0" (GABRIEL, 2013, p. 229). Caso a oferta de pós-graduação não transforme o suficiente para que as expectativas não se tornem frustrações, de todas as partes envolvidas nesse processo, novas formas potencializadas pela internet surgirão para atender à esses desejos em novos formatos de ofertas, que podem alterar toda a estrutura do campo.

\section{REFERÊNCIAS}

BITNER, M. J.; BROWN,S. W. The service imperative. Business Horizons, vol. 51, p. 39-46, 2008.

BOURROUL, Marcela. Escola gaúcha faz sucesso com cursos inusitados. Pequenas empresas e grandes negócios. Disponível em: <

http://revistapegn.globo.com/Revista/Common/0,EMI300005-17192,00

$\mathrm{ESCOLA}+\mathrm{GAUCHA}+\mathrm{FAZ}+\mathrm{SUCESSO}+\mathrm{COM}+\mathrm{CURSOS}+\mathrm{INUSITADOS} . \mathrm{html}>$ Acessado em: 16 de Setembro de 2014.

CAMP, Robert C. Benchmarking: the search for industry best practices that lead to superior performance. ASQC Quality Press, 1989.

CANUTO, Vera Regina Albuquerque. Políticos e Educadores: a organização do ensino superior no Brasil. Petrópolis: Editora Vozes, 1987.

COSTA, J. F. A influência do valor percebido pelo cliente sobre os comportamentos de reclamação e boca a boca: uma investigação em cursos de pós-graduação lato sensu. Tese (Doutorado em Administração de Empresas) - Escola de Administração de Empresas de São Paulo, São Paulo, 2007. 
COURSERA. Sobre nós. Disponível em: <https://www.coursera.org/about/>. Acessado em: 16 de Setembro de 2014.

DEMO, P. Coisas Velhas em Coisas Novas: novas "velhas tecnologias". Ciência da Informação (Impresso), v. 39, p. 108-121, 2010.

DEMO, P. DIY - Do it yourself - Chances de aprender bem 2. Humanidades \& Tecnologia em Revista (FINOM), v. 5, p. 15-48, 2013.

ENDEAVOR BRASIL. O empreendedorismo nas universidades. Disponível em: < http://www.endeavor.org.br/artigos/estrategia-crescimento/cenarios-e-tendencias/oempreendedorismo-nas-universidades $>$. Acessado em: 16 de Setembro de 2014.

FONSECA, D. M. Contribuições ao debate da pós-graduação lato sensu. Revista Brasileira de Pós-Graduação - RBPG, Vol. 1, n 2, p. 173-182, 2004.

GABRIEL, M.Educ@r: a (r)evolução digital na educação. São Paulo: Saraiva, 2013.

GONÇALVES, Carlos A.; MEIRELLES, Anthero M. Projetos e relatórios de pesquisa em Administração. São Paulo: Atlas, 2004.

HOPER. Análise Setorial do Ensino Superior Privado - Brasil. Foz do Iguaçu, 2009.

IBOPE. Técnicas projetivas. Disponível em: http://www.ibope.com.br/pt$\mathrm{br} / \mathrm{solucoes} /$ analises/tecnicasqualitativas/paginas/tecnicas-projetivas.aspx. Acessado em: 16 de Setembro de 2014.

INSTITUTE OF PLAY. About. Disponível em: < http://www.instituteofplay.org/about/>. Acessado em: 16 de Setembro de 2014.

ISOTANI, Seiji., MIZOGUCHI, Riichiro. A Relação entre Processos de Interação e o Desenvolvimento do Aluno em Sessões Colaborativas. In: Workshop sobre Informática na Escola, 2006, Campo Grande. Anais do Congresso da Sociedade Brasileira de Computação, 2006. p. 15-23.

IVY, J. A new higher education marketing mix: the 7ps for MBA marketing. International Journal of Education Management, v.22, n4, p. 288-299, 2008.

LEVY, Pierre. Cibercultura. Tradução de Carlos Irineu da Costa. São Paulo: Editora 34, 1999.

LOVELOCK, C.; WIRTZ, J.; HEMZO, M. A., Marketing de Serviços: pessoas, tecnologia e estratégia, São Paulo: Pearson Prentice Hall, $7^{\circ}$ Edição, 2011.

LOVELOCK, C; GUMMESSON, E. Whither services marketing? In search of a new paradigm and fresh perspectives. Journal of Service Research, v.7, p. 20-41, ago., 2004.

MALHOTRA, N. K. Pesquisa de marketing: uma orientação aplicada. 3. ed. Porto Alegre: Bookman, 2001. 
MINISTÉRIO DA EDUCAÇÃO. Qual a diferença entre pós-graduação lato sensu e stricto sensu?. Disponível em: http://portal.mec.gov.br/index.php?id=13072:qual-a-diferenca-entrepos-graduacao-lato-sensu-e-stricto-sensu\&option=com content. Acessado em: $15 \mathrm{de}$ Setembro de 2014.

iSchool. Who we are. Disponível em: < http://www.nycischool.org/index.php?c=3>. Acessado em: 16 de Setembro de 2014.

PILATI, O. Especialização: falácia ou conhecimento aprofundado? Revista Brasileira de PósGraduação - RBPG. Vol. 3, n 5, p. 7-26, 2006.

SAMPAIO, Helena. O setor privado de ensino superior no Brasil: continuidades e transformações. Revista Ensino Superior Unicamp - Edição nº 4 | Outubro de 2011.

SILVA JR, João dos Reis; SGUISSARDI, Valdemar. Novas faces da educação superior no Brasil. 2. Ed. Bragança Paulista, SP: USF-IFAN, 2001.

TEAM ACADEMY. Disponível em: < http://www.tiimiakatemia.fi/en/>. Acessado em: 16 de Setembro de 2014.

VERGARA, Sylvia C. Métodos de pesquisa em administração. São Paulo: Atlas, 2005.

VIEIRA, Valter. A.; TIBOLA, Fernando. Pesquisa qualitativa em marketing e suas variações: trilhas para pesquisas futuras. In: Revista de Administração Contemporânea, Curitiba, v.9, n.2, p. 9-33, Abr/Jun, 2005.

ZEITHAML, V.; BITNER, M.J.; GREMLER, D.D. Services Marketing: Intergating Customer Focus across the Firm, $4^{\circ}$ ed., McGraw-Hill Irwin, New York, NY, 2006. 